Yüzüncü Yil Üniversitesi
Tarim Bilimleri Dergisi

Araştırma Makalesi (Research Article)

\title{
Akdeniz Geçit Kuşağında Farklı Dönemlerde Olgunlaşan Bazı Elma Çeşitlerinin Performanslarının Belirlenmesi**
}

\author{
İbrahim BOLAT ${ }^{* 1}$, Mustafa YILMAZ ${ }^{2}$, Ali İKİNCí ${ }^{1}$ \\ ${ }^{1}$ Harran Üniversitesi, Ziraat Fakültesi, Bahçe Bitkileri Bölümü, Şanlıurfa, Türkiye \\ ${ }^{2}$ T. C. Tarım ve Orman Bakanlığı, Yağlı Tohumlar Araştırma Enstitüsü, Osmaniye, Türkiye \\ *Sorumlu yazar e-posta: ibolat@harran.edu.tr
}

\section{Makale Bilgileri}

Geliş: 17.10 .2018

Kabul: 11.04.2019

Online Yayınlanma 28.06. 2019

DOI: 10.29133 /yyutbd.471552

\section{Anahtar kelimeler}

Fenoloji,

Malus domestica,

Meyve kalitesi,

Pomoloji,

Verim etkinliği
Öz: Elma, farklı ekolojilerde ve oldukça geniş bir alanda yetiştiriciliği yapılan bir ılıman iklim meyvesidir. Ancak, yetiştiricilik yapılacak ekolojiye uygun çeşit önerisi için, o ekolojideki performansların incelenmesi büyük önem taşımaktadır. Çalışma, Akdeniz geçit kuşağında yetiştirilen ve değişik dönemlerde olgunlaşan Mondial Gala, Fuji ve Scarlet Spur elma çeşitlerinin performanslarının belirlenmesi amacıyla 2012-2013 yıllarında yürütülmüştür. Araştırmada, çeşitlerin bazı fenolojik özellikleri ile verim ve meyve kalite özellikleri incelenmiştir. Bulgulara göre çeşitlerde tam çiçeklenme 11 Nisan (Mondial Gala)-25 Nisan (Fuji) ve meyve olgunlaşması ise 11 Ağustos (Mondial Gala) - 5 Ekim (Fuji) tarihleri arasında gerçekleşmiştir. Çeşitlerin meyve ağırlıkları 137.50 g (Scarlet Spur) - 217.30 g (Fuji), meyve boyu 61.65 mm (Mondial Gala) - 71.03 mm (Scarlet Spur) ve meyve çapı $66.57 \mathrm{~mm}$ (Scarlet Spur) - $80.67 \mathrm{~mm}$ (Fuji) arasında değişim göstermiştir. Elma çeşitlerinde suda çözünebilir kuru madde miktarı \% 13.50 (Scarlet Spur) - \% 15.17 (Mondial Gala), titre edilebilir asit miktarı \% 0.23 (Scarlet Spur) - \% 0.40 (Fuji), indirgen şeker kapsamı \% 8.93 (Scarlet Spur) - \% 10.17 (Fuji), toplam şeker düzeyi \% 12.08 (Scarlet Spur) - \% 13.87 (Fuji) ve toplam fenol içerikleri ise $113.40 \mathrm{mg} / 100 \mathrm{~g}$ (Scarlet Spur) - 148.40 $\mathrm{mg} / 100 \mathrm{~g}$ (Fuji) arasında yer almıştır. Öte yandan, elma çeşitlerinde ağaç başına verim 4.92 (Scarlet Spur) - $9.32 \mathrm{~kg} /$ ağaç (Fuji) ve birim gövde kesit alanına düşen verim 0.28 (Scarlet Spur) - $0.66 \mathrm{~kg} / \mathrm{cm}^{2}$ (Mondial Gala) arasında değişim göstermiştir. Yaz dönemi açısından Mondial Gala, erken güz dönemi açısından Scarlet Spur ve güz dönemi için ise Fuji çeşidinin bölgede ürün çeşitliğinin sağlanması açısından üreticilere katkı sağlayacağı düşünülmektedir.

\section{Determination of the Performance of Some Apple Cultivars Matured in Different Periods in the Mediterranean Transitional Zone}

\section{Article Info}

Received: 17.10.2018

Accepted: 11.04.2019

Online Published 28.06.2019

DOI: $10.29133 /$ yyutbd.471552

\section{Keywords}

Phenology,

Malus domestica,
Abstract: Apple is a temperate climate fruit grown in different ecology and a wide range of area. However, to determine the suitable variety for every ecology, it is of great importance to investigate the performance of these varieties. This study was carried out in 2012-2013 in order to determine the performance of Mondial Gala, Fuji and Scarlet Spur apple varieties grown in Mediterranean transitional zone and matured in different periods. In this study, some phenological properties of cultivars and yield and fruit quality characteristics were investigated. According to the results, full bloom occurred in 21 to 25 April and maturation on 11 of August and 5 October. In cultivars, fruit weights in ranged between $137.50 \mathrm{~g}$ and $217.30 \mathrm{~g}$, fruit diameter $66.57 \mathrm{~mm}$ and $80.67 \mathrm{~mm}$. 
Fruit quality, Pomology, Yield efficiency
In varieties, total soluble solids showed change as $13.50 \%$ and $15.17 \%$, the amount of titratable acidity $0.23 \%$ and $0.40 \%$, reducing sugar content $8.93 \%$ and $10.17 \%$, total sugar level $12.08 \%$ and $13.87 \%$ and the total phenol content $113.40 \mathrm{mg} / 100 \mathrm{~g}$ and $148.40 \mathrm{mg} / 100 \mathrm{~g}$. On the other hand, trunk cross-sectional area of apple cultivars was found to vary between $13.20 \mathrm{~cm}^{2}$ and $22.67 \mathrm{~cm}^{2}$, yield per tree: $4.92 \mathrm{~kg} /$ tree and $9.32 \mathrm{~kg} /$ tree and the yield efficiency: $0.28 \mathrm{~kg} / \mathrm{cm}^{2}$ and $0.66 \mathrm{~kg} / \mathrm{cm}^{2}$. Mondial Gala for the summer period, Scarlet spur for the early fall period and Fuji apple cultivars for the fall period will contribute to producers in the region in terms of product diversity is thought to contribute.

\footnotetext{
** Mustafa YILMAZ’ın “Akdeniz Geçit Kuşağında Değişik Dönemlerde Olgunlaşan Bazı Elma Çeşitlerinin Performanslarının Belirlenmesi” isimli tezinden üretilmiştir.
}

\section{Giris}

Dünya üzerinde Antarktika hariç, bütün kıtalarda, 1lıman iklime sahip bölgelerde ve tropik bölgelerin yüksek rakımlı yerlerinde doğal olarak yetişen ve 30 kadar türü bulunan elma (Malus domestica Borkh.), 1lıman iklim meyveleri içerisinde en fazla üretim ve tüketim miktarlarına sahip olan türdür (Özongun ve ark., 2014).

Dünyada elma yetiştiriciliği kuzey ve güney yarı kürenin $30^{\circ}-50^{\circ}$ enlemler arasındaki 1lıman iklime sahip bölgelerine yayılmıştır (Soylu, 2003). Türkiye'de ise Ege Bölgesi’nde 500 metreden, Akdeniz ve Güneydoğu Anadolu Bölgesi'nde ise 800 metreden daha yüksek yerlerde yetişmektedir (Kaygısız, 2004; Özçağıran ve ark., 2005). Dünya elma üretimi yaklaşık 83 milyon ton olup, Türkiye 3 032164 ton ile dünya elma üretiminde Çin ve ABD'nin ardından 3. sırada gelmektedir (FAOSTAT 2017).

Elma bitkisinin birçok kültür çeşidi ve yabani formları soğuk ve sert iklim koşullarına önemli düzeyde dayanım göstermektedir. Elmanın odun dokuları kış döneminde - 35 ile - $40{ }^{\circ} \mathrm{C}^{\prime}$ ye dayanabilmektedir. Ancak, bahar döneminde açmış çiçekler - 2.2 ile $-2.3{ }^{\circ} \mathrm{C}$, küçük meyveler ise - 1.1 ile $-2.2^{\circ} \mathrm{C}$ düzeylerindeki sıcaklıklardan zarar görebilmektedir (Özcağıran ve ark., 2005; Gerçekcioğlu ve ark., 2012).

Elmada sağlıklı bir çiçeklenme meydana gelmesi ve buna dayalı olarak düzenli tozlanma ve döllenme koşullarının oluşabilmesi için tür ve çeşitlere göre değişmekle birlikte $+7.2^{\circ} \mathrm{C}$ 'nin altında 2 000 ile 3000 saat arasındaki kış soğuklanma ihtiyacının karşılanması gerekmektedir (Özbek 1978; Kaygısız, 2004; Gerçekcioğlu ve ark., 2012). Ancak, son dönemlerde 1slah çalışmaları sonucunda düşük soğuklanma isteğine sahip (400-600 saat gibi) oldukça fazla sayıda çeşit elde edilmiş ve bu sayede elmadaki yetiştiricilik alanı subtropik bölgelere doğru önemli yayılma göstermiştir (Gerçekçioğlu ve ark., 2012).

Elma bitkisi yaz dönemindeki yüksek sıcaklıklara belirli düzeye kadar bir dayanım göstermekle birlikte, genellikle $40{ }^{\circ} \mathrm{C}$ ve üzerindeki uzun süreli sıcaklıklardan ve düşük hava neminden olumsuz olarak etkilenmektedir (Özbek, 1978; Özcağıran ve ark., 2005; Gerçekcioğlu ve ark., 2012). Son 25-30 y1llık dönemde ülkemizde elma tarımında önemli gelişmeler meydana gelmiştir. Elma yetiştiriciliğinde uygulanan modern yetiştirme teknikleri sadece bu türün yetiştiriciliğindeki gelişmelerle kalmayıp, diğer meyve türlerinde de modern teknoloji kullanımına öncülük etmiştir. Elma yetiştiriciliğinde en önemli gelişme klasik çöğür anaçları yerine değişik kuvvette büyüme özelliğine sahip klonal anaçların kullanımı alanında yaşanmıştır. Bu sayede ülkemizin hemen her bölgesinde bodur veya yarı bodur büyüme özelliğine sahip klonal anaçlarla bahçeler kurulmuştur (Öztürk ve ark. 2005; Ikinci ve Bolat 2016; Atay ve Atay, 2018).

Ülkemizde toplam elma üretiminin \% 36.2'lik bölümü Akdeniz Bölgesi’nden sağlanmaktadır. Bu bölgeyi \% 18.0'lik üretim payları ile Batı ve Orta Anadolu Bölgeleri ve \% 9.8 ile Ege Bölgesi takip etmektedir (TÜİK, 2016). Akdeniz ve Güneydoğu Anadolu bölgeleri arasında bir geçiş noktasında bulunan Osmaniye ilinde 2079 da alanda 3259 ton elma üretimi yapılmakta olup, ağaç başına ortalama verim 37.4 kg'dır (TÜİK, 2016).

Osmaniye ili Akdeniz Bölgesi’nde yer almakta ve etrafının büyük bir bölümü Toros Dağları ile çevrili bulunmaktadır. Osmaniye ili Merkez ilçesi $123 \mathrm{~m}$ rakıma sahip olmakla birlikte, etrafını çeviren dağlarda yükselti 1575 m (Zorkun) - 2246 m (Düldül Dağları) aralığında değişim göstermektedir. 
Osmaniye Merkez ilçesi ve yakın çevresi Akdeniz iklimi özelliğine sahiptir. İlin yüksek rakımlı kısımlarında ise kışın daha soğuk ve yazın daha serin özelliğe sahip Akdeniz-Karasal bölgeler arasındaki geçit iklimi hüküm sürmektedir (Anonim, 2018a).

Osmaniye ili Merkez ilçesinde $+7.2^{\circ} \mathrm{C}$ 'nin altındaki toplam soğuklama süresinin $679-970$ saat arasında değişim gösterdiği bildirilmektedir (Yelmen, 2007). İlde meyvecilik tarımının yoğun olarak yapıldığı Toros dağları etekleri, Düziçi, Bahçe ve Hasanbeyli ilçeleri gibi daha yüksek rakımlı bölgelerin soğuklama sürelerine ait veri bulunmamakla birlikte, bu kesimlerin Merkez ilçeden daha uzun bir soğuklamaya sahip olduğu düşünülmektedir.

Bu çalışmada Osmaniye ili Bahçe ilçesi sınırları içerisinde bulunan, geçit iklimi özelliğine sahip alanda M9 anacı üzerine aşılı ve sık dikim uygulaması yapılan üç ayrı elma çeşidinin performanslarının incelenmesi amaçlanmıştır.

\section{Materyal ve Yöntem}

Araştırma, 2012-2013 yılları arasında Osmaniye ili Bahçe ilçesi Burgaçlı köyü Payamlı mevkiinde bulunan bir üretici bahçesinde ( $37^{\circ} 10^{\prime}$ Kuzey ve $36^{\circ} 25^{\prime}$ 'Doğu; rakımı 393 m) yürütülmüştür. Araştırma bahçesi, M9 klonal anacı üzerine aşılı Mondial Gala, Scarlet Spur ve Fuji çeşitleri ile 2008 y1lı kış döneminde $3 \times 1 \mathrm{~m}$ sıra arası ve sıra üzeri mesafede kurulmuştur. Tozlayıcı çeşit olarak Golden Delicious kullanılmıştır. Ağaçlara merkezi lider terbiye sistemi uygulanmıştır. Bahçedeki ağaçların üzeri güneş yanıklığından korunması için gölgeleme materyali ile kaplanmıştır. Araştırmanın yürütüldüğü bahçe Nisan-Ekim ayları arasında damla sulama sistemi ile sulanmış, gübreleme ve ilaçlama gibi teknik ve kültürel işlemler düzenli bir şekilde yerine getirilmiştir.

\section{İklim özellikleri}

Araştırmanın yürütüldüğü Osmaniye ilinde 1986-2014 yıllarında arasında belirlenen ortalama sicaklık $18.3{ }^{\circ} \mathrm{C}$, maksimum sicaklık $34.2{ }^{\circ} \mathrm{C}$ (Ağustos), minimum sicaklık $3.4{ }^{\circ} \mathrm{C}$ (Ocak), toplam yağış $802 \mathrm{~mm}$ ve ortalama nispi nem değeri ise \% 62.3 olarak belirtilmiştir (Anonim, 2018b).

\section{Toprak özellikleri}

Araştırmanın yürütüldüğü bahçe toprağının kimyasal özellikleri Çizelge 1.'de verilmiştir.

Çizelge 1. Araştırmanın yürütüldüğü bahçenin toprak analizi sonuçları (Bozkurt ve ark. 2001)

\begin{tabular}{|c|c|c|c|c|c|c|c|}
\hline $\begin{array}{c}\text { Toplam } \\
\text { Azot } \\
(\mathrm{N}) \\
(\%)\end{array}$ & $\begin{array}{l}\text { Alınabilir } \\
\text { fosfor } \\
\left(\mathrm{P}_{2} \mathrm{O}_{5}\right) \\
(\mathrm{kg} / \mathrm{da})\end{array}$ & $\begin{array}{c}\text { Alınabilir } \\
\text { potasyum } \\
\left(\mathrm{K}_{2} \mathrm{O}\right) \\
(\mathrm{kg} / \mathrm{da})\end{array}$ & $\begin{array}{c}\text { Alınabilir } \\
\text { kalsiyum } \\
(\mathrm{CaO}) \\
(\mathrm{kg} / \mathrm{da})\end{array}$ & $\begin{array}{c}\text { Alınabilir } \\
\text { magnezyum } \\
\text { (MgO) } \\
\text { (kg/da) }\end{array}$ & $\begin{array}{l}\text { Alınabilir } \\
\text { demir } \\
\text { (Fe) } \\
(\mathrm{kg} / \mathrm{da})\end{array}$ & $\begin{array}{l}\text { Alınabilir } \\
\text { çinko } \\
\text { (Zn) } \\
(\mathrm{kg} / \mathrm{da})\end{array}$ & $\begin{array}{c}\text { Toprak } \\
\text { (pH) }\end{array}$ \\
\hline 0.56 & 7.0 & 25.1 & 2720 & 213 & 12.5 & 0.71 & 8.00 \\
\hline Orta & Orta & Yeterli & Çok yüksek & Çok yüksek & Orta & Orta & Bazik \\
\hline
\end{tabular}

\subsection{Yöntem}

Araştırmada ele alınan elma çeşitleri üzerinde yapılan gözlemler ve ölçümler ile uygulanan metotlar aşağıda belirtilmiştir.

\section{Fenolojik gözlemler}

Fenolojik özellikler olarak; tomurcuk kabarması, tomurcuk patlaması, çiçeklenme başlangıcı, tam çiçeklenme, çiçeklenme sonu, meyvenin hasat olum tarihi ve yaprak döküm tarihleri tüm çeşitler için ayrı ayrı belirlenmiştir. Çiçeklenme başlangıcı; çiçeklerin \% 5'nin açtığ 1 , tam çiçeklenme; çiçeklerin \% 60-70'inin açtı̆̆ 1 ve çiçeklenme sonu; çiçeklerin taç yapraklarının \% 90'dan fazlasının döküldüğü tarihler olarak belirlenmiştir (Chapman and Catlin, 1976; Erdoğan ve Bolat, 2002; Yaşasın ve ark., 2006; Ikinci ve Bolat, 2016). 


\section{Meyve Özelliklerin Belirlenmesi}

İncelenen elma çeşitlerinde, çeşidin özelliklerini temsil edecek şekilde her çeşide ait her bir ağaçtan hasat döneminde alınan 10'ar meyvede; meyve ağırlığı (g) 0.01 g'a duyarlı hassas terazi (Precisa BJ 6100D) ile; meyve eni $(\mathrm{mm})$, meyve boyu $(\mathrm{mm}) 0.01 \mathrm{~mm}$ 'ye duyarl dijital kumpas (Mitutoyo CD20CPX) ile; meyve eti sertliği $\left(\mathrm{kg} \mathrm{cm}^{-2}\right)$ el penetrometresi ile; meyve hacmi, ağzına kadar saf su dolu ölçü silindirinin içine teker teker elmalar birakılarak, taşan suyun ölçü silindirinde ölçülmesi ile $(\mathrm{cm} 3)$ ve meyve tohum sayısı, meyvelerden çıkartılan tohumların sayılarak, ortalamalarının alınması ile (adet) belirlenmiştir (Burak ve ark., 1998; Yaşasın ve ark. 2006, Ikinci ve Bolat, 2016).

\section{Kimyasal Özelliklerin Belirlenmesi}

Çeşitlere ait meyvelerde toplam suda eriyebilir kuru madde (SÇKM) miktarı el refraktometresi ile \% olarak ölçülerek (Burak ve ark., 1998; Karaçalı, 2004; Yaşasın ve ark., 2006; Özrenk ve ark., 2011; Abacı ve Sevindik, 2014; Ikinci ve Bolat, 2016), titre edilebilir asitlik (TA) meyve suyu örneğinin 0.1N $\mathrm{NaOH}$ ile titre edilmesi ve harcanan baz miktarına göre malik asit cinsinden hesaplanma ile \% olarak (Karaçalı, 2004; Ikinci ve Bolat, 2016), kabuklu meyve örneğinde toplam fenolik madde (mg/100 g taze ağırlık) tayini Folin-Ciocalteu yöntemi kullanılarak (Hayoğlu ve Türkoğlu, 2007; Abacı ve Sevindik, 2014), indirgen ve toplam şeker tayinleri ise Lane-Eynon metoduna göre belirlenmiştir (Hayoğlu ve Türkoğlu, 2007; Cemeroğlu, 2010).

\section{Verim Özellikleri}

Elma çeşitlerine ait ağaçlarda ağaç başına düşen verim (kg ağaç-1), birim gövde kesit alanına düşen verim $\left(\mathrm{kg} \mathrm{cm}^{-2}\right)$ ve dekara verim $\left(\mathrm{kg} \mathrm{da}^{-1}\right)$ miktarı değerleri belirlenmiştir (Yaşasın ve ark., 2006, Ikinci ve Bolat, 2016).

\section{Istatistik Analiz}

Araştırma tesadüf blokları deneme desenine göre 3 tekerrürlü ve her tekerrürde 3 ağaç olacak şekilde kurulmuştur. Denemeden elde edilen sonuçların değerlendirilmesinde JMP 8.0 paket programı kullanılmıştır. Ortalamalar arasındaki farklılıkların karşılaştırılmasında 'LSD Testi' $(p<0.05$ ve $p<0.01)$ kullanılmıştır.

\section{Bulgular ve Tartışma}

Denemede yer alan çeşitlerde 2012 ve 2013 yıllarında yapılan fenolojik gözlemlerde; tomurcuk kabarması 14 Mart (Mondial Gala)-23 Mart (Fuji) ve tomurcuk patlaması ise 20 Mart (Mondial Gala) 31 Mart (Fuji) tarihleri arasında gerçekleşmiştir (Çizelge 2.). Çeşitler arasında en erken çiçeklenmeye Mondial Gala (3 Nisan), en geç ise Fuji (17 Nisan) başlamıştır. İncelenen üç elma çeşidinde tam çiçeklenme 11 Nisan (Mondial Gala) - 25 Nisan (Fuji) tarihleri arasında gerçekleşirken, çiçeklenme sonu ise 17 Nisan (Mondial Gala) - 05 Mayıs (Fuji) tarihleri arasında meydana gelmiştir.

Bahçe (Osmaniye) İlçesi koşullarında yapılan gözlemlerde, elma çeşitlerinde ilk hasat olgunluğuna 11 Ağustos'ta Mondial Gala çeşidi gelirken, en geç ise 5 Ekim'de Fuji çeşidi gelmiştir (Çizelge 2.). Elma çeşitlerinde tam çiçeklenmeden hasada kadar geçen süre 122 gün (Mondial Gala) ile 167 gün (Fuji) arasında değişmiştir. Elma çeşitlerinin yaprak dökümü 8 Aralık - 27 Aralık tarihleri arasında meydana gelmiştir. 
Çizelge 2. Mondial Gala, Fuji ve Scarlet Spur elma çeşitlerinde 2012 ve 2013 yılına ait bazı fenolojik gözlem sonuçları

\begin{tabular}{lcccccccc}
\hline Çeşitler & Y11 & T.K. & T.P. & Ç.B. & T.Ç. & C..S. & H.T. & T.C.H.G. \\
\hline Mondial & 2012 & 20.03 & 27.03 & 12.04 & 21.04 & 30.04 & 22.08 & 123 \\
Gala & 2013 & 14.03 & 20.03 & 03.04 & 11.04 & 17.04 & 11.08 & 122 \\
\hline Scarlet & 2012 & 21.03 & 29.03 & 14.04 & 21.04 & 29.04 & 10.09 & 142 \\
Spur & 2013 & 15.03 & 21.03 & 05.04 & 12.04 & 20.04 & 30.08 & 141 \\
\hline \multirow{2}{*}{ Fuji } & 2012 & 23.03 & 31.03 & 17.04 & 25.04 & 05.05 & 05.10 & 163 \\
& 2013 & 17.03 & 24.03 & 08.04 & 15.04 & 24.04 & 29.09 & 167 \\
\hline
\end{tabular}

T.K: Tomurcuk kabarması. T.P: Tomurcuk patlaması, Ç.B: Çiçeklenme başlangııı, T.Ç: Tam çiçeklenme, Ç.S: Çiçekleneme sonu, H.T: Hasat tarihi, T.Ç.G.S: Tam çiçeklenmeden hasada kadar geçen gün sayısı

Burak ve ark. (1994), Yalova koşullarında çöğür anacına aşılı Jerseymac çeşidinde tomurcuk kabarmasının 15 Mart, tomurcuk patlamasının 29 Mart, ilk çiçeklenmenin 16 Nisan, tam çiçeklenmenin 19 Nisan ve çiçeklenme sonunun ise 30 Nisan tarihlerinde gerçekleştiğini bildirmişlerdir. Benzer ekolojide yapılan bir başka araştırmada ise elma çeşitlerinin çiçeklenme başlangıcının 16 Mart - 21 Nisan tarihleri arasında meydana geldiği tespit edilmiştir (Yaşasın ve ark., 2006). Tokat ekolojik koşullarında yetiştirilen dört farklı elma çeşidinde ilk çiçeklenme 29 Mart -26 Nisan tarihleri arasında (Polat, 1997) olurken, Eğirdir (Isparta) ekolojik koşullarında ise ilk çiçeklenme 16 Nisan - 18 Nisan tarihleri arasında meydana gelmiştir (Atay ve ark., 2010). Atay ve ark. (2010), Eğirdir koşullarında MM 106 anacı üzerine aşılı Jerseymac, Galaxy Gala ve Braeburn çeşitlerinin 2006 yılında sırasılyla; 20, 22 ve 20 Nisan tarihlerinde tam çiçeklenme aşamasında olduğunu, 2007 yılında ise sırasıyla; 28 Nisan, 1 Mayıs ve 28 Nisan tarihlerinde tam çiçeklenme aşamasına ulaştıklarını bildirmişlerdir. Van ekolojik koşulları altında 2005-2007 yılları arasında yöresel elma genotiplerinde yapılan gözlemlerde tam çiçeklenmenin 30 Nisan - 11 Mayıs (Kaya ve Balta, 2009), Çoruh Vadisi'nde yetişen elma çeşitlerinde 8 - 22 Mayıs (Erdoğan ve Bolat, 2002) ve Tokat ekolojik koşullarında yetiştirilen elma çeşitlerinde ise 5-29 Nisan (Polat, 1997) tarihleri arasında meydana geldiği belirlenmiştir.

Özongun ve ark. (2014), Eğirdir/Isparta ekolojisinde MM 106 anacına aşılı 10 elma çeşidinde 2003-2009 yılları arasındaki fenolojik gözlem sonuçlarına göre çiçeklenme sonunun 01-05 Mayıs tarihlerinde olduğunu bildirmişlerdir. Eğirdir koşullarında yıllara göre yapılan fenolojik gözlem sonuçlarına göre M9, M26, MM 106 ve MM 111 anacı üzerine aşılı Mondial Gala elma çeşidinde tomurcuk kabarma tarihi 20-25 Mart, tomurcuk patlaması 29 Mart-5 Nisan, ilk çiçeklenme 17-21 Nisan, tam çiçeklenme 23-29 Nisan ve çiçeklenme sonu 1-7 Mayıs olarak belirlenmiştir (Özongun ve ark., 2016). Benzer şekilde ülkemizin farklı bölgelerinde değişik elma çeşitleri üzerinde yapılan çalışmalarda da çiçeklenme sonunun bölgeye ve çeşit özelliğine bağlı olarak değişim gösterdiği saptanmıştır (Polat. 1997; Atay ve ark.. 2010).

Tokat koşullarında farklı elma çeşitlerinden meyve olgunlaşmasının 5-19 Eylül (Polat 1997), Van koşullarında 22 Ağustos - 10 Ekim (Kaya ve Balta, 2009), Ordu koşullarında 25 Eylül - 17 Ekim (Yarılgaç ve ark., 2009) ve Eğirdir koşullarında 25 Ağustos- 1 Eylül (Özongun ve ark., 2016) tarihleri arasında gerçekleştiği saptanmıştır.

Araştırmamızda incelemiş olduğumuz elma çeşitlerinde 2012 yılında tam çiçeklenmeden hasada kadar geçen süre 123 gün (Mondial Gala) ile 163 gün (Fuji), 2013 yılında ise 122 gün (Mondial Gala) ile 167 gün (Fuji) olarak tespit edilmiştir (Çizelge 2.). Ülkemizin farklı bölgelerinde değişik elma çeşitleri üzerinde yapılan çalışmalarda tam çiçeklenmeden hasada kadar geçen süre Niğde ekolojik koşullarında ise 122 - 164 gün (Ceylan, 2008), Van koşullarında 102 - 150 gün (Kaya ve Balta, 2009), Tokat koşullarında 98 - 180 gün (Atay ve ark. 2010) ve Eğirdir koşullarında 142-169 gün (Seymen ve Polat, 2015) arasında değişim gösterdiği saptanmıştır.

Ülkemizin değişik yörelerinde yapılan çalışmalarda, fenolojik gözlemler bakımından birbirinden farklı sonuçlar elde edilmiştir. Meyve yetiştiriciliğinde çiçeklenme zamanı ve süresi türlere, çeşitlere, anaçlara, ekolojiye, yetiştiriciliğin yapıldığ yerin enlem-boylamına, rakımına, sıcak ve soğuk rüzgarlara, yıllara ve kültürel uygulamalara göre değişkenlik göstermektedir (Karaçalı, 2004).

Osmaniye koşullarında değişik dönemlerde olgunlaşan 3 elma çeşidi ait bazı meyve özellikleri Çizelge 3.'te verilmiştir. İncelenen meyve özellikleri bakımından çeşitler arasında istatistiksel olarak önemli $(p<0.01$ ve $p<0.05)$ düzeyde farklılıkların olduğu tespit edilmiştir. Çeşitlerin ortalama meyve ağırlığı 157.5 g (Scarlet Spur) - 212.8 g (Fuji), ortalama meyve eni 68.2 mm (Mondial Gala) - 79.3 mm 
(Fuji), ortalama meyve boyu 62.7 g (Mondial Gala) -67.5 (Scarlet Spur), ortalama meyve hacmi 166.7 ml (Mondial Gala) - 260 ml (Fuji) ve ortalama çekirdek sayıs1 6.6 adet (Scarlet Spur) - 8.7 adet (Fuji) arasında saptanmıştır.

Meyve eti sertliği bakımından Fuji çeşidi $\left(8.2 \mathrm{~kg} / \mathrm{cm}^{2}\right)$ en yüksek değeri, Scarlet Spur çeşidi ise en düşük değeri $\left(5.1 \mathrm{~kg} / \mathrm{cm}^{2}\right)$ vermiştir (Çizelge 3.). Suda çözünebilir kuru madde yönünden en yüksek değer Mondial Gala çeşidinden (\% 14.7) elde edilirken, bu çeşidi Fuji (\% 14.1) ve Scarlet Spur (\% 13.9) çeşitleri takip etmiştir. En yüksek titre edilebilir asit miktarı Fuji çeşidinde (\% 0.39), en düşük ise Scarlet Spur (\% 0.28) çeşidinde belirlenmiştir. Eğirdir (Isparta) koşullarında MM 106 anacı üzerine aş11 10 elma çeşidinin yer aldığı bir çeşit adaptasyon denemesinde, çeşitlerin meyve ağırlıkları 162 (Rubinstein) - 287 g (Crown Gold), meyve eni 69 (Early Red One) - 84 mm (Novaja), meyve boyu 57 (Gala Selecta) - 77 mm (Topred), meyve eti sertliği 6.94 (Crown Gold) - $9.55 \mathrm{~kg} / \mathrm{cm}^{2}$ (Cripps Pink (Pink Lady $\left.{ }^{\mathrm{TM}}\right)$ ), SÇKM içeriği \% 12.20 (Scarlet spur) - 16.40 (Cripps Pink (Pink Lady ${ }^{\mathrm{TM}}$ )) ve asitlik değeri \% 0.31 (Topred) - \% 1.12 (Cripps Pink (Pink Lady ${ }^{\mathrm{TM}}$ )) arasında belirlenmiştir (Özongun ve ark., 2014). Konya ekolojisine uygun yeni elma çeşitlerinin belirlenmesi amacıyla yürütülen bir çalışmada, M9 anacına aşılı Fuji elma çeşidinde ortalama meyve ağırlı̆̆ $142.33 \mathrm{~g}$, meyve eni $68.43 \mathrm{~mm}$, meyve boyu $58.59 \mathrm{~mm}$, çekirdek sayıs 8.83 adet, meyve eti sertliği $4.96 \mathrm{~kg} / \mathrm{cm}^{2}$, SÇKM miktarı \% 12.40 ve titre edilebilir asit miktarı ise \% 0.48 olarak belirlenmiştir (Arıkan ve ark., 2015). Samsun ekolojik şartlarında yetiştirilen bazı elma çeşitlerinde ortalama meyve ağırlığı 112.3 (Jersey Mac) - 173.9 g (Starkrimson Delicious), meyve eni 64.83 (Golden Delicious) - 74.27 mm (Granny Smith), meyve boyu 54.55 (Jersey Mac) - 63.74 mm (Red Chief), meyve eti sertliği 4.94 (Jersey Mac)-7.98 kg/cm² (Granny Smith), SÇKM \% 10.46 (Starkrimson Delicious) - \% 13.45 (Cooper 7 SB2 ve Golden Delicious) ve TA \% 0.39 (Süper Chief) - \% 0.90 (Granny Smith) arasında değişim göstermiştir (Öztürk ve Öztürk, 2016). Eğirdir koşullarında M9 anacı üzerine aşılı Mondial Gala çeşidinin meyve ağırlığı, meyve eni, meyve boyu, meyve eti sertliği, SÇKM ve TA sırasıyla; $147 \mathrm{~g}, 69.04 \mathrm{~mm}, 61.73 \mathrm{~mm}, 9.25 \mathrm{~kg} / \mathrm{cm}^{2}, \% 13.03$, 3.70 ve \% 0.30 arasında tespit edilmiştir (Özongun ve ark., 2016).

En önemli sekonder metabolitlerinden olan toplam fenolik madde içeriği incelenen çeşitlerde 119.10 mg/100 g (Scarlet Spur) - 145.25 mg/100 g (Fuji) arasında değişim göstermiştir (Çizelge 3.). Benzer şekilde Ardahan ekolojik koşullarında yetiştirilen elma çeşitlerinin meyve kabuğunda fenolik madde miktarları 209.7-578.9 mg/100 g, meyve etinde - ise 50.2 ile $112.2 \mathrm{mg} / 100 \mathrm{~g}$ arasında değişim gösterdiği saptanmıştır (Abacı ve Sevindik, 2014). Diğer taraftan Özden ve Özden (2014), olgunluk dönemindeki elma meyvelerindeki toplam fenolik madde içeriğini $698.67 \mathrm{mg} / \mathrm{GAE} / \mathrm{kg}$ (Granny Smith) - $810.48 \mathrm{mg} / \mathrm{GAE} / \mathrm{kg}$ (Gala) arasında yer aldığını belirlemiş̧lerdir.

Üç farklı elma çeşidinde indirgen şeker kapsamının \% 9.13 (Scarlet Spur) - \% 10.09 (Fuji) arasında değiştiği belirlenmiştir (Çizelge 3.). İndirgen şeker kapsamı üzerine yapılan istatistiki analizlerde, Mondial Gala ve Scarlet Spur çeşitleri aynı grupta, Fuji çeşidi ise farklı grupta yer almıştır. Ülkemizin farklı bölgelerinde değişik elma çeşitlerinde yapılan çalışmalarda da meyvedeki indirgen şeker kapsamı bakımından çeşitlere göre farklılıklar olduğu tespit edilmiştir. Nitekim, indirgen şeker kapsamı Çoruh Vadisi'nde yetişen elma çeşitlerinde \% 5.30 (Fındık) - \% 8.69 (Golden Delicious) (Erdoğan ve Bolat, 2002) arasında; Erzurum, Kars, Erzincan ve Gümüşhane koşullarında yetiştirilen elmalarda \% 8.11 (Amasya) - \% 10.06 (Göbek) (Keleş, 1979) arasında ve Erzincan koşullarında yetiştirilen elmalarda ise \% 6.96 (Granny Smith) - \% 8.97 (Golden Delicious) (Güleryüz ve ark., 2001) arasında değiştiği belirlenmiştir. Çeşitlerin toplam şeker içerikleri \% 12.38 (Scarlet Spur) -\% 13.74 (Fuji) aralığında değişim göstermiştir (Çizelge 3.). Ülkemizin farklı bölgelerinde değişik elma çeşitleri üzerinde yapılan çalışmalarda; Çoruh Vadisi koşullarında yetiştirilen elma çeşitlerinde \% 8.38 (Fındık) - \% 12.72 (Golden Delicious) (Erdoğan ve Bolat, 2002) ve Erzincan koşullarında yetiştirilen elma çeşitlerinde ise \% 9.04 (Granny Smith) - \% 11.84 (Sakı) (Güleryüz ve ark., 2001) arasında toplam şeker içeriği tespit edilmiştir. Diğer taraftan Teletar (1985), olgunluk dönemindeki elma meyvelerindeki toplam şeker içeriğinin \% 9.56 (Amasya) - \% 13.09 (Hüryemez) arasında değiştiğini saptamıştır.

Ülkemizin farklı ekolojilere sahip olan yörelerinde yürütülen araştırmalarda, aynı çeşit ve anaç bileşenleri kullanılmış olsa dahi, elma çeşitlerinin meyve kalite özellikleri ve kimyasal içeriklerinde kısmen birbirinden farklı sonuçlar elde edilmiştir. Değişik çalışmalarla, yürütülmüş olan bu çalışma arasındaki farklılığın çeşit, anaç, meyve tutum oranlarının farklı olmasından, kültürel uygulamalardan, iklim ve toprak özelliklerinden, yetiştiriciliğin yapıldığı yerin enlem-boylam ve rakımından kaynaklandığı düşünülmektedir. 
Bahçe (Osmaniye) İlçesi koşullarında M9 anacı üzerine aşı1ı 4 yaşlı Mondial Gala, Scarlet Spur ve Fuji elma çeşitleri arasında, ağaçlardan elde edilen veya hesaplama ile belirlenen tüm verim değerleri arasında istatistiksel anlamda önemli fark bulunmuştur (Çizelge 4.). Elma çeşitlerinden 2012-2013 y1llarında elde edilen ağaç başına ortalama verim değerlerinin $6.40 \mathrm{~kg} /$ ağaç (Scarlet Spur) - $7.89 \mathrm{~kg} / \mathrm{ağaç}$ (Fuji) arasında değişim gösterdiği saptanmıştır. Ağaç başına verim değerini Niğde koşullarında değişik elma çeşitleri üzerinde yapılan benzer bir çalışmada $-10.48 \mathrm{~kg} /$ ağaç (Galaxy Gala/M9) - $17.34 \mathrm{~kg} / \mathrm{ağaç}$ (Granny Smith/M9) (Ceylan, 2008), Tokat koşullarında $3.24 \mathrm{~kg} / \mathrm{ağaç} \mathrm{-} 6.82 \mathrm{~kg} / \mathrm{ağaç} \mathrm{(Gala/M9)}$ (Küçüker ve ark., 2011) ve Çorum koşullarında $10.10 \mathrm{~kg} / \mathrm{ağaç} \mathrm{(Red} \mathrm{Chief/M9)} \mathrm{-} 16.60 \mathrm{~kg} / \mathrm{ağaç} \mathrm{(Granny}$ Smith/M9) (Çulha, 2010) arasında yer aldığı tespit edilmiştir.

Denemede yer alan elma çeşitlerine ait ağaçlarda $14.51 \mathrm{~cm}^{2}$ (Mondial Gala) $-20.74 \mathrm{~cm}^{2}$ (Fuji) arasında gövde enine kesit alanı değerleri ölçülmüştür. Farklı elma çeşitlerinde Tokat koşullarında 2.09 $\mathrm{cm}^{2}$ (Delcorf) - $3.69 \mathrm{~cm}^{2}$ (Red Star) (Özkan ve ark., 2009), Yalova koşullarında $28.10 \mathrm{~cm}^{2}$ (Red Chief) - $494.63 \mathrm{~cm}^{2}$ (Mutsu) (Akçay ve ark., 2009) ve Tokat koşullarında $4.36 \mathrm{~cm}^{2}$ (Gala) - $20.51 \mathrm{~cm}^{2}$ (Gala) (Küçüker ve ark., 2011) arasında gövde enine kesit alanı tespit edilmiştir.

Birim gövde kesit alanına düşen verim miktarları (verim etkisi =etkili verim) göz önüne alındığında, en yüksek değer Mondial Gala $\left(0.50 \mathrm{~kg} / \mathrm{cm}^{2}\right)$ çeşidinden elde edilirken, en düşük ise Fuji çeşidinde $\left(0.39 \mathrm{~kg} / \mathrm{cm}^{2}\right)$ tespit edilmiştir. Görükle (Bursa) ekolojik koşulları altında farklı elma çeşitlerinin etkili verim değerinin $0.15 \mathrm{~kg} / \mathrm{cm}^{2}$ (Elstar, Topred) - $0.39 \mathrm{~kg} / \mathrm{cm}^{2}$ (Granny Smith) (Soylu ve ark., 2003), Tokat koşullarında $0.16 \mathrm{~kg} / \mathrm{cm}^{2}$ (Jonagold) - $0.40 \mathrm{~kg} / \mathrm{cm}^{2}$ (Gala) (Baytekin ve Akça 2011), Yalova koşullarında $0.49 \mathrm{~kg} / \mathrm{cm}^{2}$ (Stark Earliest) - $2.79 \mathrm{~kg} / \mathrm{cm}^{2}$ (Starkrimson Delicious) (Akçay ve ark., 2009) arasında yer aldığı bildirilmiştir.

Elma çeşitlerinde iki yılın ortalamasına göre belirlenen dekara verim değerlerine göre; en yüksek dekara verim $2628 \mathrm{~kg}$ ile Fuji çeşidinde belirlenirken, bu çeşidi Mondial Gala (2367 kg) ve Scarlet Spur (2135 kg) çeşitleri izlemiştir. Tokat koşullarında elma ağaçlardan elde edilen dekara verim değerleri 1238 - 1925 kg/da (Küçüker ve ark., 2011) arasında, Niğde koşullarında 2324 kg/da (Scarlet Spur) - $3326 \mathrm{~kg} / \mathrm{da}$ (Super Chief) (Özdemir ve ark. 2009) ve Samsun koşullarında ise $791 \mathrm{~kg} / \mathrm{da}$ (Skyline Supreme/MM 111) - 6655 kg/da (Granny Smith/MM 106) (Kaplan ve Macit, 2009) arasında değişim gösterdiği belirtilmiştir.

Çalışmamızda; verim değerleri ve gövde enine kesit alanı ile ilgili elde edilen bulgular, ülkemizin farklı yörelerinde yürütülen çalışmalarda elde edilen bulgularla bazı durumlarda benzerlik, bazı durumlarda ise farklılık gösterdiği belirlenmiştir. Bulgular arasındaki farklılığın; çalışmalardaki anaç, çeşit, kültürel uygulamalar, iklim, toprak ve ağacın yaşı gibi özelliklerin farklılık göstermesinden kaynaklandığı düşünülmektedir. 
Çizelge 3. Mondial Gala, Scarlet Spur ve Fuji elma çeşitlerinin bazı meyve özellikleri (2012-2013 yılı ortalaması)

\begin{tabular}{|c|c|c|c|c|c|c|c|c|c|c|c|}
\hline Çeşitler & $\begin{array}{l}\text { Meyve } \\
\text { ağırlığ1 } \\
\text { (g) }\end{array}$ & $\begin{array}{l}\text { Meyve eni } \\
(\mathrm{mm})\end{array}$ & $\begin{array}{l}\text { Meyve } \\
\text { boyu } \\
(\mathrm{mm})\end{array}$ & $\begin{array}{l}\text { Meyve } \\
\text { hacmi } \\
\left(\mathrm{cm}^{3}\right)\end{array}$ & $\begin{array}{l}\text { Çekirdek } \\
\text { sayısı } \\
\text { (adet) }\end{array}$ & $\begin{array}{l}\text { Meyve eti } \\
\text { sertliği } \\
\left(\mathrm{kg} / \mathrm{cm}^{2}\right)\end{array}$ & $\begin{array}{l}\text { SÇKM } \\
\text { (Briks) }\end{array}$ & $\begin{array}{l}\text { Titre } \\
\text { edilebilir } \\
\text { asitlik } \\
\text { (\%) }\end{array}$ & $\begin{array}{l}\text { Toplam } \\
\text { fenol } \\
\text { (mg/100g } \\
\text { taze ağırlık) }\end{array}$ & $\begin{array}{l}\text { İndirgen } \\
\text { şeker } \\
\text { kapsamı } \\
(\%)\end{array}$ & $\begin{array}{l}\text { Toplam } \\
\text { şeker } \\
(\%)\end{array}$ \\
\hline Mondial Gala & $169.8 b^{z}$ & $68.2 \mathrm{~b}$ & $62.7 \mathrm{~b}$ & $166.7 \mathrm{c}$ & $7.3 \mathrm{~b}$ & $7.4 \mathrm{~b}$ & $14.7 \mathrm{a}$ & $0.36 \mathrm{ab}$ & $122.80 \mathrm{~b}$ & $9.40 \mathrm{~b}$ & $12.97 \mathrm{ab}$ \\
\hline Scarlet Spur & $157.5 \mathrm{~b}$ & $68.7 \mathrm{~b}$ & $67.5 \mathrm{a}$ & $225.5 \mathrm{~b}$ & $6.6 \mathrm{~b}$ & $5.1 \mathrm{c}$ & $13.9 \mathrm{~b}$ & $0.28 \mathrm{~b}$ & $119.10 \mathrm{~b}$ & $9.13 \mathrm{~b}$ & $12.38 \mathrm{~b}$ \\
\hline Fuji & $212.8 \mathrm{a}$ & $79.3 \mathrm{a}$ & $65.4 \mathrm{ab}$ & $260.0 \mathrm{a}$ & 8.7 a & $8.2 \mathrm{a}$ & $14.1 \mathrm{~b}$ & $0.39 \mathrm{a}$ & $145.25 \mathrm{a}$ & 10.09 a & $13.74 \mathrm{a}$ \\
\hline LSD 0.05 & $15.17^{*}$ & $6.60^{*}$ & $3.63^{* *}$ & $34.36^{*}$ & $1.06^{* *}$ & $0.75^{* *}$ & $0.34^{* *}$ & $0.07^{* *}$ & $17.30^{* *}$ & $0.43^{* *}$ & $0.86^{* *}$ \\
\hline
\end{tabular}

${ }^{\mathrm{z}}$ Aynı sütunda aynı harfle işaretlenmiş ortalamalar arasında istatistiksel bakımdan fark yoktur $(\mathrm{P}<0.05)$.

*:\% 5 ve **: \% 1 düzeylerinde önemli. Ö.D.:Önemli Değil

Çizelge 4. Mondial Gala, Scarlet Spur ve Fuji elma çeşitlerine ait ağaçların gövde enine kesit

alanı, ağaç başına verimi, dekara verimi ve etkili verim değerleri (2012-2013 yılı ort.)

\begin{tabular}{lllll}
\hline & & $\begin{array}{l}\text { Gövde enine } \\
\text { kesit alanı } \\
\left(\mathrm{cm}^{2}\right)\end{array}$ & $\begin{array}{l}\text { Birim gövde } \\
\text { kesit alanına } \\
\text { düşen verim } \\
\left(\mathrm{kg} \mathrm{cm}^{-2}\right)\end{array}$ & $\begin{array}{l}\text { Birim alana } \\
\text { düşen verim } \\
\left(\mathrm{kg} \mathrm{da}^{-1}\right)\end{array}$ \\
\hline Monditler & $\begin{array}{l}\text { Verim } \\
(\mathrm{kg} / \mathrm{ağaç})\end{array}$ & $14.51 \mathrm{c}$ & $0.50 \mathrm{a}$ & $2367.0 \mathrm{~b}$ \\
Scarlet Spur & $7.10 \mathrm{~b}^{\mathrm{z}}$ & $15.99 \mathrm{~b}$ & $0.41 \mathrm{~b}$ & $2135.5 \mathrm{c}$ \\
Fuji & $6.40 \mathrm{c}$ & $20.74 \mathrm{a}$ & $0.39 \mathrm{~b}$ & $2628.0 \mathrm{a}$ \\
& $7.89 \mathrm{a}$ & $0.46^{* *}$ & $0.065^{* *}$ & $120.19^{* *}$ \\
\hline
\end{tabular}

${ }^{\mathrm{z}}$ Aynı sütunda aynı harfle ișaretlenmis ortalamalar arasında istatistiksel bakımdan fark yoktur $(\mathrm{P}<0.05)$.

**: \% 1 düzeylerinde önemli. 


\section{Sonuç}

Doğu Akdeniz Bölgesi'nde yer alan Osmaniye ilinde genellikle kışlar 1lıman geçmektedir. Osmaniye'de öteden beri ağırlıklı olarak tarla tarımı yapılmakta, meyvecilik sektörünün tarımsal üretimdeki payı ise oldukça düşük düzeydedir. İlde eskiden elma yetiştiriciliği hemen hemen hiç yapılmamaktaydı. Ancak, son yıllarda ülkemize giren yeni çeşitler, Osmaniye ili üreticilerinin de dikkatini çekmiş ve uygun alanlarda özellikle bodur anaçlarının kullanıldığı, soğuklama isteği fazla olmayan elma çeşitlerinin kullanıldı̆̆ 1 ve sık dikim sistemlerinin uygulandığ 1 elma bahçeleri tesis edilmeye başlanmıştır.

Mondial Gala, Scarlet Spur ve Fuji elma çeşitleri ülkemizde son dönemlerde önemli derecede yaygınlık gösteren ve pazar değerleri yüksek olan çeşitlerdir. Bu çeşitler ülkemizde hemen her bölgede yetiştirilmekle birlikte, Akdeniz Bölgesi ve İç Anadolu Bölgesi arasındaki geçit konumu özelliği gösteren Doğu Akdeniz havzasının yüksek kesimleri için (özellikle soğuklama ve renklenme ile ilgili sorunların ortadan kalkması nedeniyle) çok daha büyük bir potansiyel taşımaktadır.

Araştırmanın yürütüldüğü geçit iklimi özelliği gösteren lokasyonda, üzerinde çalışılan üç elma çeşidinde de bitki gelişimi, verim ve meyve kalitesi açısından önemli bir sorunla karşılaşılmamıştır. Gerek kendi verilerimizden ve gerekse diğer bölgelerde yapılan çalışmalardan elde edilen bulguların ışığında, yaz dönemi açısından Mondial Gala, erken güz dönemi açısından Scarlet Spur ve güz dönemi açısından ise Fuji elma çeşidinin, bölgedeki elma tarımı yapılabilecek benzer alanlarda ürün çeşitliğinin sağlanması açısından üreticilere katkı sağlayacağı düşünülmektedir.

\section{Kaynakça}

Abacı, Z. T., \& Sevindik, E. (2014). Ardahan bölgesinde yetiştirilen elma çeşitlerinin biyoaktif bileşiklerinin ve toplam antioksidan kapasitesinin belirlenmesi. Yüzüncü Yıl Üniversitesi Tarım Bilimleri Dergisi, 24(2), 175-184.

Akçay, M. E., Doğan, A., Burak, M., Yaşasın, A. S., \& Öz, F. (2009). Bazı elma çeşitlerinin Marmara Bölgesinde yapılan adaptasyon çalışmaları. Tarım Bilimleri Araştırma Dergisi, 2(2), 65-71.

Anonim. (2018a). http, //www.osmaniye.gov.tr Erișim tarihi: 06 Ekim 2018.

Anonim. (2018b). Osmaniye Meteoroloji İl Müdürlüğ̈ İklim verileri.

Arıkan, Ş., İpek, M., \& Pırlak, L. (2015). Konya ekolojik şartlarında bazı elma çeşitlerinin fenolojik ve pomolojiközelliklerinin belirlenmesi. Türk Tarım - Gıda Bilim ve Teknoloji Dergisi, 3(10), 811815.

Atay, A. N., \& Atay, E. (2018). Elma 1slahında ve çeşit yönetiminde yenilikçi eğilimler. Yüzüncü Yıl Üniversitesi Tarım Bilimleri Dergisi, 28(2), 234-240.

Atay, E., Prrlak, L., \& Atay, A. N. (2010). Determination of fruit growth in some apple varieties. J. of Agric. Sci., 16, 1-8.

Baytekin, S., \& Akça, Y. (2011). M9 elma anacı üzerine aşılı farklı elma çeşitlerinin performanslarının belirlenmesi. Gaziosmanpaşa Üniversitesi Ziraat Fakültesi Dergisi, 28(1), 45-51.

Burak, M., Büyükyılmaz, M., \& Öz, F, (1998). Marmara Bölgesi için ümitvar elma çeşitlerinin seçimi. Bahçe, 27, 107-119.

Bozkurt, M. A., Yarılgaç, T., \& Çimrin, K. M. (2001). Çeşitli meyve ağaçlarında beslenme durumlarının belirlenmesi. Yüzüncü Yıl Üniversitesi Tarım Bilimleri Dergisi, 11(1), 39-45.

Ceylan, F. B., (2008). Bodur ve yarı bodur anaçlar üzerine aşılı bazı elma çeşitlerinin Niğde ekolojik şartlarında fenolojik ve pomolojik özelliklerinin tespiti (Yayımlanmamış yüksek lisans tezi). Selçuk Üniversitesi, Fen Bilimleri Enstitüsü, Konya, 56s.

Çulha, A. E. (2010). Çorum ekolojik şartlarında M9 anacına aşılı bazı elma çeşitlerinin fenolojik ve pomolojik özelliklerinin tespiti (Yayımlanmamış yüksek lisans tezi). Selçuk Üniversitesi, Fen Bilimleri Enstitüsü, Konya, 54s.

FAOSTAT. (2017). FAO Statistical database. http, // faostat.fao.org/site/567/DesktopDefault.aspx Erişim tarihi: 02 Mart 2019.

Gerçekçioğlu, R., Bilgener, Ş., \& Soylu, A. (2012). Genel meyvecilik (Meyve yetiştiriciliğin esaslarl). Nobel Akademik Yayıncılık Eğitim ve Danışmanlık Tic. Ltd. Şti., Ankara, 486s. 
Güleryüz, M., Ercişli, S., \& Erkan, E. (2001). Erzincan ovasında yetiştirilen bazı elma çeşitlerinin meyve gelişimi dönemlerinde meydana gelen fiziksel ve kimyasal değişimler ile bunlar arasındaki ilişkiler. Atatürk Üniversitesi Ziraat Fakültesi Dergisi, 32(1), 51-59.

Hayoğlu, İ., \& Türkoğlu, H. (2007). Meyve-sebze işleme teknolojisi dersi uygulama ders notları. Harran Üniversitesi Ziraat Fakültesi, Gıda Mühendisliği Bölümü, Şanlıurfa, 42s.

Ikinci, A., \& Bolat, I. (2016, October). Determination of phenological, pomological and yield characteristics of low chilling apple cultivars budded on M9 and MM 106 rootstocks. VIII International Scientific Agricultural Symposium "Agrosym 2016" içinde (627-636. ss.). Jahorina, Bosnia and Herzegovina.

Kaplan, N., \& Macit, İ. (2009). Samsun koşullarında bazı elma çeşitlerinin bitkisel gelişimi ve verimliliği üzerine elma klon anaçlarının etkisi. Tar. Bil. Araş. Derg., 2(2), 159-166.

Karaçalı, İ. (2004). Bahçe ürünlerinin muhafaza ve pazarlanması (4. Baskl). Ege Üniv. Ziraat Fakültesi Yayınlar1 No: 494, İzmir, 413s.

Kaya, T., \& Balta, F. (2009). Van yöresi elma seleksiyonları 1: Periyodisite göstermeyen genotipler. Tarım Bilimleri Araştırma Dergisi, 2(2), 25-30.

Kaygısız, H. (2004). Elma yetiştiriciliği. Hasad Yayıncılık Ltd. Şti., İstanbul, 148 s.

Küçüker, E., Özkan. Y., \& Yıldız, K. (2011). Farklı terbiye sistemi uygulanmış M9 anacına aşılı Gala (Malus domestica Borkh.) elma çeşidinde erken dönem performansının belirlenmesi. Batı Akdeniz Tarımsal Araştırma Enstitüsü Derim Dergisi, 28(1), 25-36.

Özbek, S. (1978). Elma yetiştiriciliği. Özel meyvecilik (Kışın yaprağını döken meyve türleri) (s. 15-94). Çukurova Üniversitesi Ziraat Fakültesi Yayınları, Yayın No: 128, Ders Kitabı: 11, Adana.

Özçağıran, R., Ünal, A., Özeker, E., \& İsfendiyaroğlu, M. (2005). Ilıman iklim meyve türleri, Yumuşak çekirdekli meyveler. Cilt, II. Ege Üniversitesi Ziraat Fakültesi Yayınları No: 556. Bornova, İzmir, 220s.

Özden, M., \& Özden, A. E. (2014). Farklı renkteki meyvelerin toplam antosiyanin, toplam fenolik kapsamlarıyla toplam antioksidan kapasitelerinin karşılaştırılması. Gıda Teknolojileri Elektronik Dergisi, 9(2), 1-12.

Özongun, Ş., Dolunay, E. M., Öztürk, G., \& Pektaş, M. (2014). Eğirdir (Isparta) şartlarında bazı elma çeşitlerinin performansları. Meyve Bilimi, 1(2), 21-29.

Özongun, Ş., Dolunay, E. M., Pektaş, M., Öztürk, G., \& Çalhan, Ö. (2016). Farklı klon anaçları üzerinde bazı elma çeşitlerinin verim ve kalite değişimleri. Ege Üniv. Ziraat Fak. Derg., 53(1), 35-42.

Özrenk, K., Gündoğdu, M., Kaya, T., \& Kan, T. (2011). Çatak ve Tatvan yörelerinde yetiştirilen yerel elma çeşitlerinin pomolojik özellikleri. Tarım Bilimleri Dergisi, 21(1), 57-63.

Öztürk, A., \& Öztürk, B. (2016). Samsun ekolojisinde yetiştirilen standart bazı elma çeşitlerinin fenolojik ve pomolojik özelliklerinin belirlenmesi. Anadolu Tarım Bilimleri Dergisi, 31, 1-8.

Öztürk, G., Özongun, S., Akgül, H., Kaymak, K., \& Eren, İ, (2005). Bodur elma yetiştiriciliği. Eğirdir Bahçe Kültürleri Araştırma Enstitüsü, Çiftçi Eğitim Serisi 13, Isparta, 44s.

Polat, M. (1997). Tokat koşullarında farklı gelişme kuvvetlerine sahip anaçlar üzerine aşılanmış elma çeşitlerinin fenolojik ve pomolojik özellikleri üzerine bir araştırma (Yayımlanmamış yüksek lisans tezi). Gaziosmanpaşa Üniversitesi, Fen Bilimleri Enstitüsü, Tokat, 101s.

Seymen, T., \& Polat, M. (2015). Bazı Amasya elma tiplerinin fenolojik, pomolojik özelliklerinin belirlenmesi ve morfolojik karakterizasyonu. Harran Tartm ve Glda Bil. Derg., 19(3), 122-129.

Soylu, A. (2003). Elma. Ilıman iklim meyveleri-II, Yumuşak çekirdekli meyveler (s.1-75). Uludağ Üniversitesi Ziraat Fakültesi Ders Notları, No: 72, Bursa.

Soylu, A., Ertürk, Ü., Mert, C., \& Öztürk, Ö. (2003). MM 106 anacı üzerine aş1lı elma çeşitlerinin Görükle koşullarındaki verim ve kalite özelliklerinin incelenmesi II. Uludă Üniversitesi Ziraat Fakültesi Dergisi, 17(2), 57-65.

TÜIKK. (2016). Türkiye İstatistik Kurumu, Tarım İstatistikleri. $\underline{\text { https, }}$ //biruni.tuik.gov.tr/bitkiselapp/bitkisel.zul Erişim tarihi: 06 Ekim 2018.

Yaşasın, A. S., Burak, M., Akçay, M.E., Türkeli, Y., \& Büyükyılmaz, M. (2006). Marmara Bölgesi için ümitvar elma çeşitleri - V. Bahçe, 35(1-2), 75-82.

Yelmen, H. (2007). Doğu Akdeniz Bölgesinde farkl soğuklama yöntemleri kullanılarak olasilıklı soğuklama süre haritalarının çıkarılması (Yayımlanmamış yüksek lisans tezi). Çukurova Üniversitesi, Fen Bilimleri Enstitüsü, Adana, 119s. 